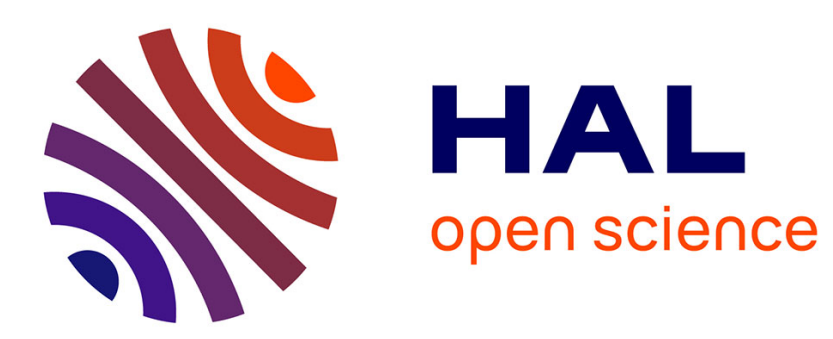

\title{
Modelling the nanoscale patterning of nucleic acid base pairs deposited onto graphite
}

Tiffany Walsh

\section{To cite this version:}

Tiffany Walsh. Modelling the nanoscale patterning of nucleic acid base pairs deposited onto graphite. Molecular Physics, 2008, 106 (12-13), pp.1613-1619. 10.1080/00268970802225533 . hal-00513213

\section{HAL Id: hal-00513213 \\ https://hal.science/hal-00513213}

Submitted on 1 Sep 2010

HAL is a multi-disciplinary open access archive for the deposit and dissemination of scientific research documents, whether they are published or not. The documents may come from teaching and research institutions in France or abroad, or from public or private research centers.
L'archive ouverte pluridisciplinaire HAL, est destinée au dépôt et à la diffusion de documents scientifiques de niveau recherche, publiés ou non, émanant des établissements d'enseignement et de recherche français ou étrangers, des laboratoires publics ou privés. 


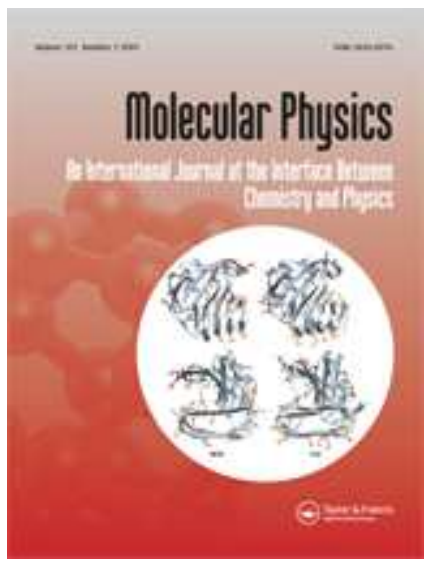

\section{Modelling the nanoscale patterning of nucleic acid base pairs deposited onto graphite}

\begin{tabular}{|r|l|}
\hline Journal: & Molecular Physics \\
\hline Manuscript ID: & TMPH-2008-0053.R1 \\
\hline Manuscript Type: & Full Paper \\
\hline $\begin{array}{r}\text { Date Submitted by the } \\
\text { Author: }\end{array}$ & 22-May-2008 \\
\hline Complete List of Authors: & Walsh, Tiffany; University of Warwick \\
\hline Keywords: & interactions, DNA, surfaces, nanoscale \\
\hline $\begin{array}{l}\text { Note: The following files were submitted by the author for peer review, but cannot be converted } \\
\text { to PDF. You must view these files (e.g. movies) online. }\end{array}$ \\
\hline mp-revis-tmph2008-0053.tex \\
\hline
\end{tabular}

\section{s scholarONE" \\ Manuscript Central}




\title{
Modelling the nanoscale patterning of nucleic acid
}

\section{base pairs deposited on graphite}

\author{
T. R. Walsh* \\ Dept. of Chemistry and Centre for Scientific Computing, University of Warwick, \\ Coventry, CV4 7AL, U.K.
}

May 22, 2008

\begin{abstract}
Interactions between graphite and nucleic-acid base pairs are investigated. An existing polarizable potential that uses distributed multipoles up to and including quadrupoles is extended to describe the graphite surface and the nucleic-acid bases cytosine and guanine. Adsorption energies and structures calculated with this potential are compared with data obtained using electronic structure theory. Structures of co-adsorbed cytosine and guanine layers are optimised and two competing arrangements, the 'dimer-row' and 'quartet-row' patterns, are compared with experimental scanning tunneling microscopy images.We include two factors not considered in previous studies: the presence of the graphite surface and the inter-row packing. However, our findings agree with previous calculations in that the 'quartet-row' is energetically preferred, despite STM experiments suggesting the 'dimer-row' structure is observed.
\end{abstract}

*t.walsh@warwick.ac.uk 


\section{Introduction}

Supramolecular self-assembly on surfaces is an area of significant technological interest. ${ }^{1,2}$ The patterns that form between surface-deposited molecules can be controlled via the balance between molecule-molecule and molecule-surface non-bonded interactions. Nanostructures formed by co-adsorption of complementary DNA bases onto graphite surfaces, observed using scanning tunneling microscopy (STM), have been recently reported. ${ }^{3}$ These authors reported self-consistent charge density-functional tight-binding (SCC-DFTB) calculations on two gas-phase (unsupported) structural models: the 'dimer-row' structure and the 'quartet-row' structure, as shown in Figure 1. Xu et al. found the 'quartet-row' to be energetically preferred-however, the 'dimer-row' structure was assigned on the basis of the STM images. It is well-known that there are pitfalls associated with assigning structures from STM data alone, where a number of viable structures, each with very similar lattice parameters, may exist. $^{4}$

Although a number of gas-phase modelling studies exist for guanine and cytosine planar interactions, ${ }^{3,5-9}$ the effect of the presence of the surface has yet to be explored. Furthermore, stabilisation due to inter-row interactions has also not been considered; both of these factors may contribute to a stabilisation of the 'dimer-row' structure over the 'quartet-row' structure, and therefore recover the structural assignment based on the experimental STM data.

First-principles calculations will not be a practical approach for directly investigating either of these aspects. However, it has been shown that semi-empirical and force-field approaches can exhibit uneven performance when probing the interactions between DNA bases. ${ }^{7,10}$ To this end, here we have constructed an extension of the AMOEBA ${ }^{11-13}$ force-field that can describe interactions between cytosine, guanine and a graphite surface. The AMOEBA force-field is distinct from many others due to a) description of electrostatics via the distributed multipole approximation, up to and including quadrupoles, and $\mathbf{b}$ ) inclusion of atom-based polarizabilities to model induction effects. In previous work, we successfully modified this potential to describe the interaction between peptides and single-walled carbon nanotubes. ${ }^{14}$ We have validated this force-field against first-principles calculations and have then applied this force-field to investigate whether the presence of the graphite, or the inter-row 
interactions, or both, lead to a match with the reported STM images.

\section{Methods}

The force-field developed in this work is an extension of the AMOEBA force-field. ${ }^{11-13}$ Atom-centred distributed multipoles up to and including the quadrupole were obtained using the distributed multipole analysis ${ }^{15,16}$ via the GDMA program, ${ }^{17}$ using input wave functions calculated with GAUSSIANO3 ${ }^{18}$ at the HF/6-31G* level of theory. In terms of multipole orientation, the " $\mathrm{z}$-then- $\mathrm{x}$ " convention for assigning local axes ${ }^{11}$ was followed throughout. For obtaining the graphite parameters, we used dodecabenzocoronen, a polyaromatic hydrocarbon (PAH) with 19 fused rings $\left(\mathrm{C}_{54} \mathrm{H}_{18}\right)$, to model the graphite sheet, as shown in Figure 2.

Distributed multipoles were calculated for a carbon atom in the central ring of the molecule, such that the influence from the terminating hydrogens at the PAH edges could be minimised. As expected, no charge was localised on the PAH carbon atoms in the centre ring, but there was a non-negligible dipole and quadrupole moment present on each of these atoms. The value of the polarizability of the carbon atoms in graphite were guided by previous calculations, ${ }^{19-21}$ and was set to $1.2 \AA^{3}$ per atom. For the cytosine and guanine molecules, we first optimised the structures at the MP2/aug-cc-pVDZ 22 level of theory. In terms of generating wave functions (for input into GDMA), each atom in each molecule was treated as a unique atomic site, resulting in 13 and 16 separate wave function calculations at the $\mathrm{HF} / 6-31 \mathrm{G}^{*}$ level for cytosine and guanine respectively. The van der Waals and polarization parameters were taken from existing parameters for similar atom types.

These extensions to the AMOEBA potential were tested in two ways: first, by minimising the geometries of several heteropairs and homopairs of guanine and cytosine, and secondly by calculating interaction energy profiles of each of the bases adsorbed onto the 19-ring PAH. All tests were ran using the TINKER package. ${ }^{23}$ The interaction energy for each minimised homopair/heteropair geometry was also calculated within TINKER, using the supermolecule approach. For the heteropair and homopair calculations, we compared with existing electronic structure theory results. ${ }^{5,6,8,9}$ For the adsorption onto the graphite surface 
(as approximated by the 19-ring PAH), there are no published electronic structure theory data. Therefore, our adsorbed geometries were used as input for first-principles interaction energy calculations using the GAUSSIAN03 package. The 6-31G* basis set was used throughout, and all interaction energies were calculated using the supermolecule method, and were corrected for basis-set superposition error using the counterpoise-correction method. ${ }^{24}$ The Hartree-Fock + Wilson-Levy (HFWL) approach was employed, which has been recently shown to give a reliable description of aromatic-aromatic non-bonded interactions ${ }^{25}$ at short to medium-ranged intermolecular separations.

The 'dimer-row' and 'quartet-row' structures were modelled in various ways. First, we modelled the unsupported (free) structures of a single row, of size range comprising from two Watson-Crick (WC) pairs up to eight WC pairs. We then re-optimised the geometry of each single row structure (dimer-row or quartet-row, comprising $6 \mathrm{WC}$ pairs) adsorbed onto a free (non-periodic) rectangular graphene sheet (of dimension roughly $37 \AA \times 43 \AA$ ), modelling the basal plane of graphite. The dimensions of this sheet were chosen such that it could accommodate three rows (each row comprising six WC pairs) in total. We then constructed triads of 'dimer-row' and 'quartet-row' structures, and arranged these in a number of starting geometries based on two motifs: $h h h$ (head-to-tail, head-to-tail, head-to-tail arrangement of rows) and tht (tail-to-head, head-to-tail, tail-to-head arrangement of rows). These triads were optimised as free-standing patterns, and were then re-optimised as adsorbed onto the graphene sheet. All AMOEBA optimisations were performed with the TINKER package.

\section{Results and Discussion}

Table 1 gives the summarised comparison of the AMOEBA interaction energies of the gas-phase homopair and heteropair geometries of cytosine (C) and guanine (G) ( as shown in Figure 3) with the AMOEBA interaction energies. While not matching the absolute energies of the $a b$ initio and DFT calculations, the overall trend in the AMOEBA energies agrees very well. We believe that it is critical to obtain good agreement with geometries other than the WC structure (which is lowest in energy with our model) since the inter-row interactions 
might involve pairings other than WC. Further, the hydrogen-bonding geometry of the WC base-pair (geometry $C_{8} \bar{G}_{10}$ in Figure 3 ) is in excellent agreement with ab initio calculations; the three heavy-atom to heavy-atom distances in the AMOEBA-optimised structure are 2.91, 3.08 and $3.03 \AA$, while the corresponding ab initio distances ${ }^{5}$ are 2.92, 3.04 and $3.02 \AA$, giving a 'short-long-long' hydrogen-bonding pattern.

We then compared our surface adsorption interaction energy profiles for cytosine and guanine, using a face-to-face geometry as shown in Figure 2. With AMOEBA we obtain an optimum cytosine interaction energy of $-31.4 \mathrm{~kJ} \mathrm{~mol}^{-1}$ at a ring-surface separation of $3.3 \AA$. Similarly we obtained an optimum guanine interaction energy of $-46.1 \mathrm{~kJ} \mathrm{~mol}^{-1}$ at a separation of $3.3 \AA$. The corresponding values from the HFWL calculations are -29.5 $\mathrm{kJ} \mathrm{mol}^{-1}(3.2 \AA)$ and $-36.9 \mathrm{~kJ} \mathrm{~mol}^{-1}(3.2 \AA)$ for cytosine and guanine respectively. Again, while the exact values do not match, we note the AMOEBA ratio of molecule-molecule to molecule-surface interaction energies agrees very well with the results from first-principles calculations. We consider this to be a useful comparison since it is precisely this ratio of interaction energies that should control nanoscale pattern formation on the surface. ${ }^{2}$ Both the AMOEBA and HFWL data are consistent with experimental observations that guanine is more strongly bound to graphite than cytosine. ${ }^{26}$ We recognise that differences might also be attributed to the fact that we are comparing energies calculated using the 19-ring PAH and not a graphite sheet.

Following this, we constructed and optimised free-standing dimer-row and quartet-row structures comprising two, three, four and six WC pairs. In each case the optimised rows maintained planarity. Table 2 summarises the energy difference for each system size, showing that the quartet-row structure is energetically preferred at all sizes, in agreement with Xu et al. ${ }^{3}$ Based on the extrapolation predictions of Xu et al., we did not see the need for increasing the size of a single row beyond this point. We propose that the energy difference can be attributed at least in part to the interfacing of the 'short-long-long' hydrogen-bonding pattern of each WC pair along the row. For the quartet-row arrangement, the pattern along the row follows a 'short-long-long, long-long-short' sequence. However, the dimer-row pattern follows a 'short-long-long, short-long-long' sequence; with concomitant distortion of the 
WC-WC interfacial hydrogen-bonds along the row. It follows that in all finite-sized quartet-row patterns there exists two types of quadruplex - one that involves a small separation between adjacent WC pairs, and one that involves a larger separation (see Figure 1). There is a distinct energetic ordering for these two ways of arranging adjacent WC pairs. AMOEBA-optimised quartet-row structures with 'small' and 'large' inter-pair spacings yield a calculated energy difference of $52.7 \mathrm{~kJ} \mathrm{~mol}^{-1}$, with the small spacing being preferred. We then re-optimised these structures using density functional theory (DFT) calculations; specifically the PBE exchange-correlation functional ${ }^{27}$ with the 6-31++G** basis. These DFT calculations again demonstrated the small spacing motif to be lower in energy by $54.5 \mathrm{~kJ} \mathrm{~mol}^{-1}$; validating that AMOEBA can recover differences in quadruplex energetics, as well as for dimer structures. Therefore, all quartet-row patterns with an even number of WC pairs will contain an odd number of adjacent WC...WC pairings that must alternate between 'large' and 'small'; accordingly, each of these quartet row structures has two entries in Table 2. We note that these energetic effects will not be important in the case of an infinitely long chain. For the dimer-row structure, the adjacent WC pairs interact with an energy similar to that of the 'large' spacing in the quartet row; our AMOEBA calculations on 2 WC pairs supports only a $0.94 \mathrm{~kJ} \mathrm{~mol}^{-1}$ difference in favour of the 'large' (quartet) spacing. Analogous PBE/6-31++G** calculations are similar; giving an energy difference of 0.45 $\mathrm{kJ} \mathrm{mol}^{-1}$, this time in the favour of the dimer-row pairing of the WC pairs. It is sufficient to say that both methods predict these two models to be essentially isoenergetic; this provides further validation of the AMOEBA potential for structures other than homoand hetero-pairings. This means that, e.g. the energetic difference between a 6 WC-pair dimer-row and a similar quartet-row with large, small, large, small, large (lslsl) intra-row patterning amounts more or less to twice the energy difference between the 'small' and 'large' WC...WC pairings. Finally, for the case of six WC pairs, we checked the effect of the surface interactions by optimising the graphene-adsorbed geometries. Again, the energetics are summarised in Table 2, and show that the preference for a single quartet-row has been maintained upon adsorption to the surface, albeit with a slightly diminished energetic 
advantage. We also explored the effect of orientation of the single row adsorbed on the graphene sheet, and found no significant difference in the overwhelming degree of preference for the quartet-row structure.

Finally, we optimised the geometry of a triad of rows (each with six WC pairs per row) as a free-standing pattern, with both the $h h h$ and tht motifs. Again, the optimised structures maintained reasonable planarity throughout. Despite numerous searches, we found the $h h h$ structures to always yield the lowest energy. However, despite what appears to be favourable shape effects due to row-row packing in the dimer-row case, as shown in Figure 4, the quartet-row structure (with slsls intra-row patterning) remained the lowest in energy. The relative energies for the dimer-row and quartet-row ( $l s l s l$ intra-row patterning) were roughly $614 \mathrm{~kJ} \mathrm{~mol}^{-1}$ and $234 \mathrm{~kJ} \mathrm{~mol}^{-1}$ respectively. Although the chains of the quartet-row structure (Figure 4) cannot approach as closely (as evidenced by the slightly longer $a$ lattice parameter, vide infra), and while the quartet-row yields a less well-packed structure (compared with the interdigitated guanine and cytosine packing in the dimer-row structure), these factors do not seem to be sufficient to overcome the energetic dominance of the single-row structures. We decomposed each triad in terms of the individual row energies and did not find significant deviation from the single-chain values as obtained earlier. We therefore do not attribute the $h h h$ energy difference to significant intra-row distortion. We also checked the orientation of the molecular dipoles in both dimer-row and quartet-row patterns, but could discern no deciding factor; both patterns support favourable relative orientations of the dipoles.

When these structures were re-optimised as adsorbed onto the graphene sheet, the quartet-row slsls structure was again preferred, with an energy difference of around 595 $\mathrm{kJ} \mathrm{mol}^{-1}$ with respect to the dimer-row structure. This again demonstrates that the presence of the graphene sheet tends to slightly decrease the energetic differences between the dimer-row and quartet-row structures, rather than alter the energetic ordering of these structures. The structures based on the tht motif remained substantially higher in energy when adsorbed onto the graphene sheet, and do not appear to be competitive. Although we have not utilised periodic boundary conditions in this work, we have made a 
rough estimate of the lattice parameters (as indicated in Figure 4) of the different surface patterns ( $a, b$, and $\theta$, the angle between the vectors, as defined by $\mathrm{Xu}$ et al.). We estimate values of $a, b$, and $\theta$ for the dimer-row pattern to be $1.32 \mathrm{~nm}, 0.75 \mathrm{~nm}$ and $80.7^{\circ}$ respectively. Xu et al. estimated corresponding values of $1.71 \pm 0.18 \mathrm{~nm}, 0.69 \pm 0.07 \mathrm{~nm}$ and $84.1 \pm 2.4^{\circ}$ respectively. Similarly, the corresponding lattice parameters for the quartet-row slsls structure are $1.35 \mathrm{~nm}, 1.52 \mathrm{~nm}$, and $80.0^{\circ}$ respectively. Despite not being lowest in energy, the dimer-row parameters show the better match between theory and experiment, although the inter-row separation $(a)$ and the angle $\theta$ are still not within experimental tolerances. However, this might be attributed to edge effects due to the finite graphene sheet. We have also not considered the effects of temperature on the lattice parameters. Since this force-field is entirely amenable to simulation approaches, in future we will perform molecular simulations at finite temperature, and within periodic boundary conditions.

The extended AMOEBA potential appears to recover trends in both the dimer and quadruplex structures of guanine and cytosine, giving credibility to the description of the intra-row interactions considered here. However, we note that our potential does relatively over-bind a number of the dimer pairings; notably the $\mathrm{WC}_{\text {pair }}$ and the $\mathbf{G}_{6} \mathbf{G}_{6}$ and $C_{7} G_{6}$ pairs. It is entirely possible that this may bias the description of inter-row interactions, although none of the dimer pairings studied here appear to resemble the intra-row configurations arising from this work. Further, it seems reasonable to assert that the inter-row interactions noted here are not dominated by hydrogen-bonding, but rather by dispersion and repulsion. Given that the existing set of dimer pair models selected in previous electronic structure theory studies are dominated by hydrogen bonds, it appears that new structural models are required to properly test and quantify our description of the inter-row interactions; two candidates are indicated on Figure 4. While DFT may fare reasonably well in describing hydrogen-bonded systems, it is not clear that DFT will perform so convincingly ${ }^{25}$ for these inter-row models, implying that some large post-Hartree-Fock calculations will be required as reliable benchmarks.

To summarise, these preliminary results indicate that the favourable intra-row 


\section{Conclusions}

We have developed an extension of an existing polarizable force-field to enable description of the interactions amongst the nucleic-acid bases cytosine and guanine, and the graphite surface. We validated our description against existing and new first-principles calculations. We investigated the influences of both the molecule-surface interaction, and inter-chain packing, upon adsorption patterns of cytosine and guanine deposited on graphite. We found that chain-chain packing effects did not reverse the energetic ordering of the dimer-row and quartet-row structures, with the quartet-row being lowest in energy. While the energetic ordering of these structures is in disagreement with the experimental data, reasonable agreement with the experimental lattice parameters is found for our calculated dimer-row structure. Exploration of kinetic effects in the formation of these structures will be the subject of a future study.

\section{Acknowledgments}

The author gratefully acknowledges the computing facilities of the Centre for Scientific Computing, University of Warwick. 


\section{References}

[1] Feyter, S. D. And Schryver, F. C. D., 2003, Chem. Soc. Rev., 32, 139.

[2] Barth, J. V., Costantini, G., And Kern, K., 2005, Nature , 437, 671.

[3] Xu, S. L., Dong, M. D., Rauls, E., Otero, R., Linderoth, T. R., And BenenbaCher, F., 2006, Nano Lett. , 6, 1434.

[4] Kelly, R. E. A. And Kantorovich, L., 2005, Surf. Sci. , 589, 139.

[5] Šroner, J., LeszCZYnski, J., And Hobza, P., 1996, J. Phys. Chem. , 100, 1965.

[6] Kabeláč, M. And Hobza, P., 2001, J. Phys. Chem. B., 105, 5804.

[7] Furukawa, M., Tanaka, H., And Kawai, T., 2001, J. Chem. Phys. , 115, 3419.

[8] Kelly, R. E. A., Lee, Y. J., And Kantorovich, L. N., 2005, J. Phys. Chem. B., 109, 22045.

[9] Kelly, R. E. A. and Kantorovich, L. N., 2007, J. Phys. Chem. C., 111, 3883.

[10] Hobza, P., Hubálek, F., Kabeláč, M., Mejzlík, P., Šponer, J., And VondrášEK, J., 1996, Chem. Phys. Lett. , 257, 31.

[11] Ren, P. And Ponder, J. W., 2002, J. Comp. Chem. , 23, 1497.

[12] Ren, P. And Ponder, J. W., 2003, J. Phys. Chem. B., 107, 5933.

[13] Ponder, J. W. And Case, D. A., 2003, Adv. Protein Chem., 66, 27.

[14] Tomásio, S. D. And Walsh, T. R., 2007, Mol. Phys. , 105, 221.

[15] Stone, A. J., 1981, Chem. Phys. Lett. , 83, 233.

[16] Stone, A. J. And Alderton, M., 1985, Mol. Phys. , 56, 1047.

[17] Stone, A. J., 2005, J. Chem. Theory Comput., 1, 1128. 
[18] Frisch, M. J., Trucks, G. W., Schlegel, H. B., Scuseria, G. E., Robb, M. A., Cheeseman, J. R., Montgomery, Jr., J. A., Vreven, T., Kudin, K. N., Burant, J. C., Millam, J. M., Iyengar, S. S., Tomasi, J., Barone, V., Mennucci, B., Cossi, M., Scalmani, G., Rega, N., Petersson, G. A., Nakatsuji, H., Hada, M., Ehara, M., Toyota, K., Fukuda, R., Hasegawa, J., Ishida, M., Nakajima, T., Honda, Y., Kitao, O., NaKai, H., Klene, M., Li, X., Knox, J. E., Hratchian, H. P., Cross, J. B., Bakken, V., Adamo, C., Jaramillo, J., Gomperts, R., Stratmann, R. E., Yazyev, O., Austin, A. J., Cammi, R., Pomelli, C., Ochterski, J. W., Ayala, P. Y., Morokuma, K., Voth, G. A., Salvador, P., Dannenberg, J. J., Zakrzewski, V. G., DAPPrich, S., Daniels, A. D., Strain, M. C., Farkas, O., Malick, D. K., Rabuck, A. D., Raghavachari, K., Foresman, J. B., Ortiz, J. V., Cui, Q., Baboul, A. G., Clifford, S., Cioslowski, J., Stefanov, B. B., Liu, G., Liashenko, A., Piskorz, P., Komaromi, I., Martin, R. L., Fox, D. J., Keith, T., Al-Laham, M. A., Peng, C. Y., Nanayakkara, A., Challacombe, M., Gill, P. M. W., Johnson, B., Chen, W., Wong, M. W., Gonzalez, C., And Pople, J. A., Gaussian 03, Revision B.05, Gaussian, Inc., Wallingford, CT, 2004.

[19] Carlos, W. E. And Cole, M. W., 1980, Surf. Sci. , 91, 339.

[20] Crowell, A. D. And Brown, J. S., 1982, Surf. Sci. , 123, 296.

[21] Zhao, X. And Johnson, J. K., 2005, Molec. Simulat. , 31, 1.

[22] Dunning, T., 1992, J. Chem. Phys. , 90, 1007.

[23] Ponder, J. W., Ren, P., Pappu, R. V., Hart, R. K., Hodgson, M. E., Cistola, D. P., Kundrot, C. E., AND RiCHARDS, F. M., 2004, TINKER - software tools for molecular design, Washington University School of Medicine, version 4.2 edn.

[24] Boys, S. F. And Bernardi, F., 1970, Mol. Phys. , 19, 553.

[25] Walsh, T. R., 2005, Phys. Chem. Chem. Phys., 7, 443. 
[26] Sowerby, S. J., Cohn, C. A., Heckl, W. M., And Holm, N. G., 2001, Proc. Natl. Acad. Sci. USA, 98, 820.

[27] Perdew, J. P., Burke, K., And Ernzerhof, M., 1996, Phys. Rev. Lett. , 77, 3865.

[28] Mamdouh, W., Dong, M. D., Su, S. L., Rauls, E., And Besenbacher, F., 2006, J. Am. Chem. Soc. , 128, 13305. 
Table 1: Interaction energies $\left(\mathrm{kJ} \mathrm{mol}^{-1}\right)$ of selected heteropair and homopair structures for cytosine $(\mathrm{C})$ and guanine $(\mathrm{G})$, optimised using the extended AMOEBA force-field. Comparisons are made with the DFT results of Kelly et al., ${ }^{8,9}$ and with the post-Hartree-Fock (AB INITIO) results of Hobza and co-workers. ${ }^{5,6}$ Our structures are labelled according to the nomenclature of Kelly et al.

\begin{tabular}{llll}
\hline Structure & AMOEBA & DFT & AB INITIO \\
\hline$C_{8} \bar{G}_{10}$ & -147.2 & -116.7 & $-99.6^{a} /-108.0^{b}$ \\
$C_{7} G_{6}$ & -138.0 & -102.3 & $-83.0^{a} /-92.90^{b}$ \\
$C_{5} \bar{G}_{2}$ & -71.1 & -65.6 & $-63.2^{b}$ \\
$C_{7} \bar{G}_{1}$ & -78.2 & -63.7 & $-59.8^{b}$ \\
$C_{5} G_{1}$ & -70.4 & -62.7 & $-59.8^{b}$ \\
$G_{6} G_{6}$ & -133.4 & -108.1 & $-92.6^{a}$ \\
$G_{9} \bar{G}_{10}$ & -84.2 & -72.4 & $-71.1^{a}$ \\
$G_{1} G_{1}$ & -40.5 & -37.6 & $-38.9^{a}$ \\
$C_{5} C_{5}$ & -98.9 & -83.9 & $-73.22^{a}$ \\
\hline
\end{tabular}

$a$ from Ref 5.

$b$ from Ref 6 . 
Table 2: Energy differences $\left(\mathrm{kJ} \mathrm{mol}^{-1}\right)$ between same-sized, single dimer-row (D) and quartetrow $(\mathrm{Q})$ structures for a range of row sizes. Each structure is signified by the number of WC pairs, and are from optimisation of free-standing patterns unless indicated otherwise. For the quartet-row structures, the pattern of small(s) and large(l) inter-pair spacings is also indicated.

\begin{tabular}{ll}
\hline Structure & $\Delta E$ \\
\hline 2D & $\mathbf{5 3 . 5}$ \\
2Q(l) & $\mathbf{5 2 . 7}$ \\
2Q(s) & 0.0 \\
\hline 3D & $\mathbf{5 4 . 1 3}$ \\
3Q & 0.0 \\
\hline 4D & $\mathbf{1 0 8 . 2}$ \\
4Q(lsl) & $\mathbf{5 3 . 0}$ \\
4Q(sls) & 0.0 \\
\hline 6D & $\mathbf{1 6 3 . 4}$ \\
6Q(lslsl) & $\mathbf{5 3 . 0}$ \\
6Q(slsls) & 0.0 \\
\hline 6D (adsorbed) & $\mathbf{1 4 5 . 4}$ \\
6Q (lslsl, adsorbed) & $\mathbf{5 6 . 5}$ \\
6Q (slsls, adsorbed) & 0.0 \\
\hline
\end{tabular}




\section{Figure Captions}

Figure 1. Examples of the dimer-row (left) and quartet-row (right) structures. The 'large' and 'small' inter WC-pair spacings are indicated for the quartet-row structure.

Figure 2. Structures used in the HFWL and AMOEBA validation calculations of the molecule-surface interaction. Left; the 19-ring polyaromatic hydrocarbon, centre; the cytosine-PAH geometry, right; the guanine-PAH geometry.

Figure 3. Geometries of AMOEBA-optimised homopairs and heteropairs of guanine and cytosine. The labels correspond with those in Table 1.

Figure 4. Structures of the lowest-energy triad motif $(h h h)$ for both the dimer-row (left) and quartet-row (right) patterns. Lattice vectors are indicated for each pattern. Two (of several) suggested candidate structural models of inter-row packing are highlighted. 

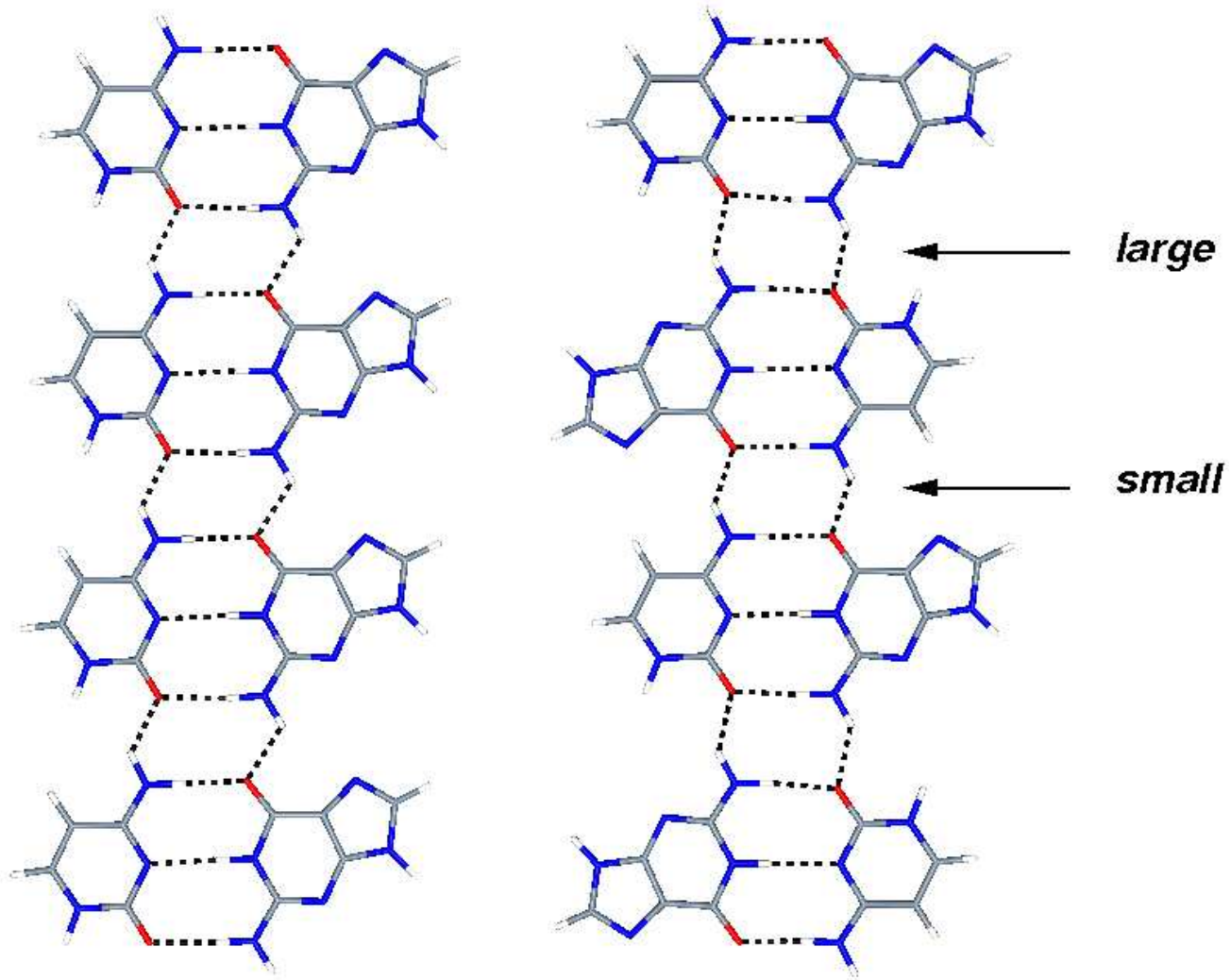

URL: http://mc.manuscriptcentral.com/tandf/tmph 


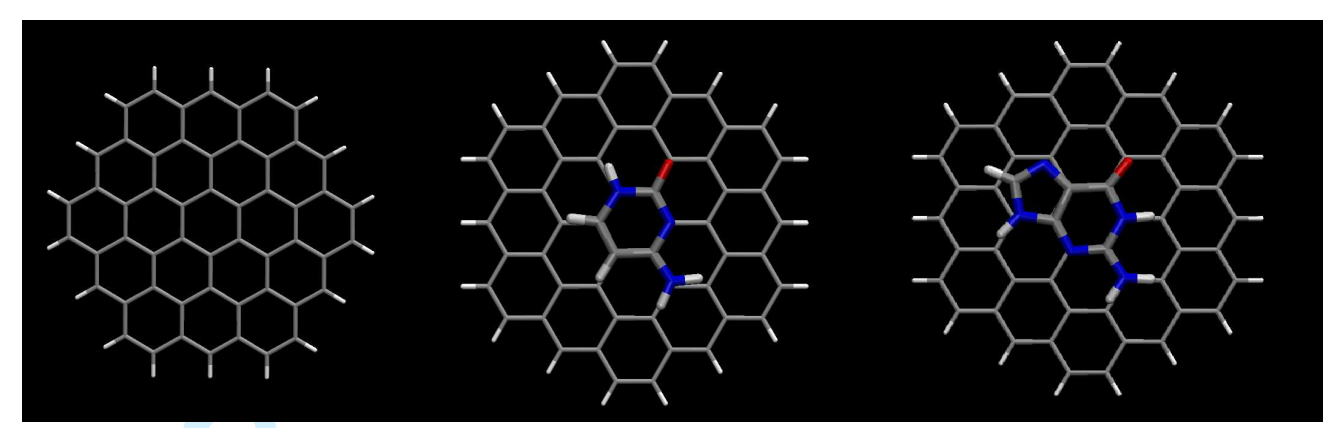

1

2

3

4

5
6

7

8

10

11

12

13

14

15

16

17

18

19

20

21

22

23

24

25

26

27

28

29

30

31

32

33

34

35

36

37

38

39

40

41

42

43

44

45

46

47

48

49

50

51

52

53

54

55

56

57

58

59

60

URL: http://mc.manuscriptcentral.com/tandf/tmph 

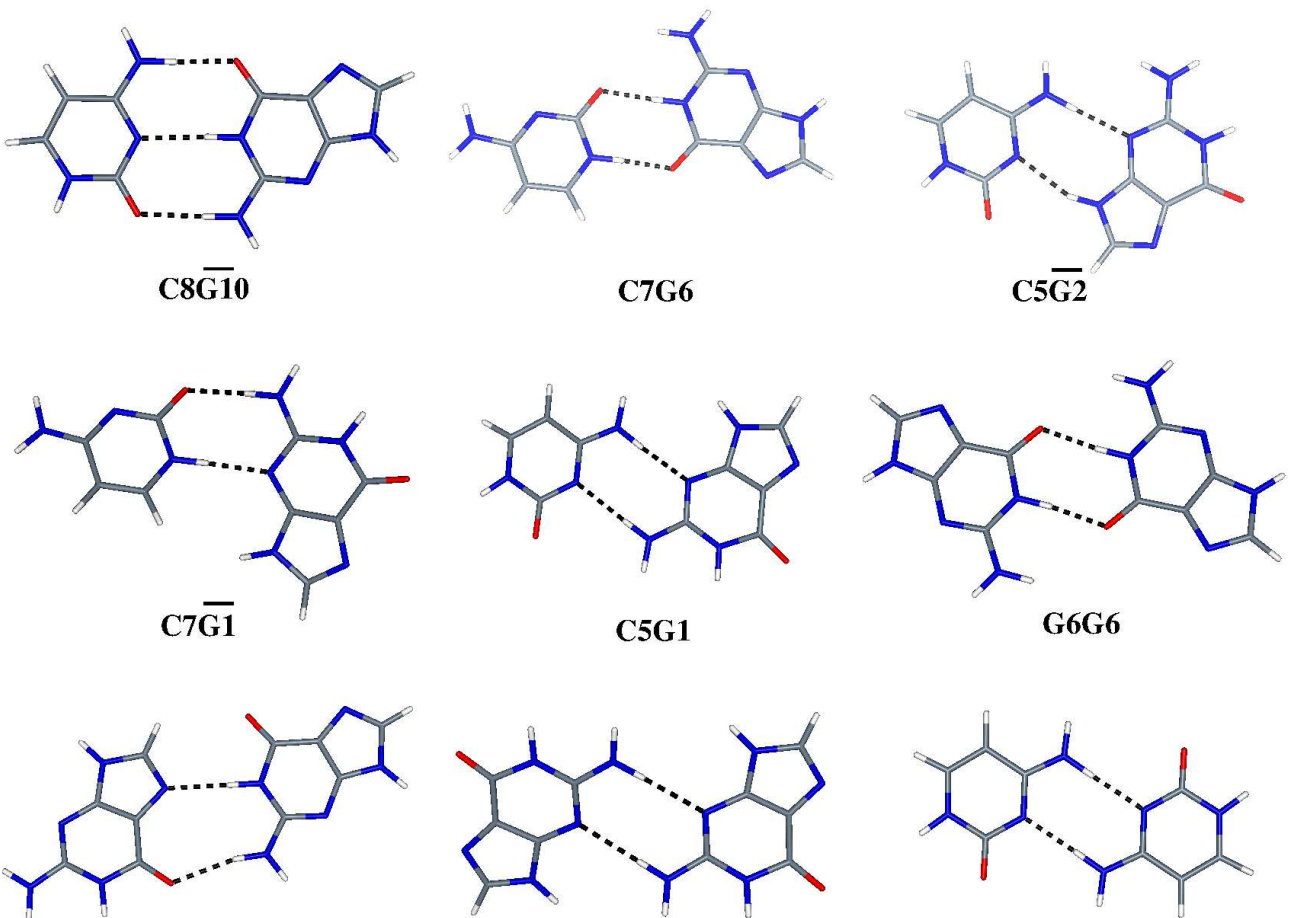

G9 $\overline{\mathrm{G10}}$

G1G1

C5C5 

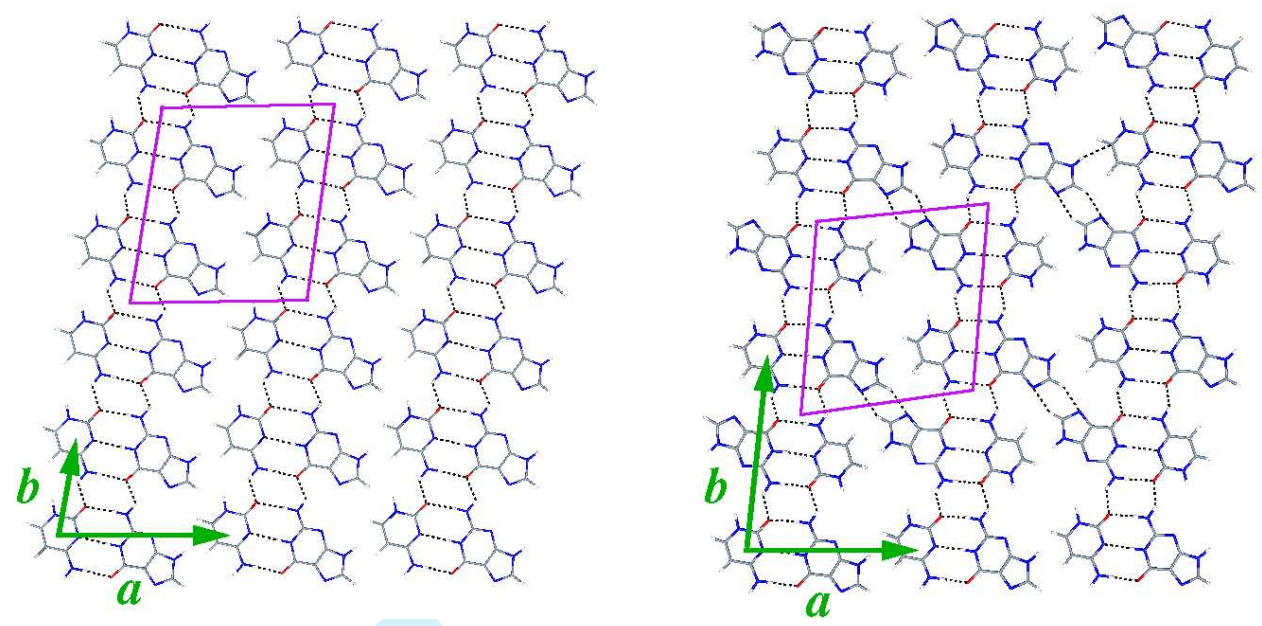

URL: http://mc.manuscriptcentral.com/tandf/tmph 